\title{
Effects of temperature on size-at-terminal molt and molting frequency in snow crab Chionoecetes opilio from two Canadian Atlantic ecosystems
}

\author{
Earl G. Dawe ${ }^{1, *}$, Darrell R. Mullowney ${ }^{1}$, Mikio Moriyasu ${ }^{2}$, Elmer Wade ${ }^{2}$ \\ ${ }^{1}$ Fisheries and Oceans Canada, Northwest Atlantic Fisheries Centre, PO Box 5667, St. John's, Newfoundland and Labrador, \\ A1C 5X1 Canada \\ ${ }^{2}$ Fisheries and Oceans Canada, Gulf Fisheries Centre, PO Box 5030, Moncton, New Brunswick, E1C 9B6 Canada
}

\begin{abstract}
The effect of temperature on molting frequency and size-at-terminal molt of the snow crab Chionoecetes opilio was investigated and compared between 2 Canadian Atlantic ecosystems based on spring and summer surveys. We found that the size-at-terminal molt was directly related to temperature but that the effect of temperature was much clearer and occurred at smaller sizes for females than for males. By focusing on recently molted (new-shelled) crabs, we showed that size-at-terminal molt is conditioned by temperature over a variable number of instars and intermolt periods leading up to the terminal molt. Crabs of both sexes larger than about $50 \mathrm{~mm}$ carapace width (CW), on annual molting schedules, sometimes skipped a molt. The frequency of skip-molting differed between the areas and sexes, and was directly related to size and inversely related to temperature. We develop a hypothesis to explain the relationships of terminal size with temperature and molting frequency that is consistent with life-history theory and snow crab bioenergetics and considers differences between the sexes. The implications to natural mortality and recruitment to fisheries are also discussed.
\end{abstract}

KEY WORDS: Snow crab · Terminal molt $\cdot$ Molting frequency $\cdot$ Size $\cdot$ Temperature $\cdot$ Atlantic Canada Resale or republication not permitted without written consent of the publisher

\section{INTRODUCTION}

The commercial fishery for snow crab Chionoecetes opilio in Atlantic Canada began in the mid1960s in the southern Gulf of St. Lawrence (sGSL) and rapidly expanded to cover fishing grounds along the Canadian coast and continental shelf from southern Nova Scotia to southern Labrador. These fishing areas are currently divided into 61 management zones with total landings of approximately $84000 \mathrm{t}$ valued at 280 million Canadian dollars in 2010 (Moriyasu 2011). The snow crab is a highly stenothermal subarctic species, inhabiting very cold waters of about $-1.5^{\circ} \mathrm{C}$ to $4^{\circ} \mathrm{C}$ (Dawe \& Colbourne 2002, Orensanz et al. 2007, Sainte-Marie et al. 2008). Fisheries in the northwest Atlantic are conducted on the New- foundland and Labrador shelf, in the Gulf of St. Lawrence (GSL), and on the Eastern Scotian Shelf (ESS) (see Fig. 1), with Newfoundland and Labrador and the sGSL accounting for most of the landings in most years (FRCC 2005). All Atlantic Canadian snow crab fisheries target only males, with a minimum legal size of $95 \mathrm{~mm}$ carapace width (CW). Snow crabs undergo a terminal molt across a broad size range (Hartnoll et al. 1993, Conan \& Comeau 1986). Males terminally molt over a broader size range than females, such that females do not grow to the minimum legal size of the fishery. In Atlantic Canada, the size-at-terminal molt ranges about 40 to $150 \mathrm{~mm}$ (postmolt) carapace width (CW) in males (SainteMarie \& Hazel 1992, Sainte-Marie et al. 1995) compared to about 30 to $95 \mathrm{~mm}$ (postmolt) CW in females 
(Alunno-Bruscia \& Sainte-Marie 1998). Most males terminally molt at one of 5 successive instars, whereas most females terminally molt (and achieve maturity) at one of 2 successive instars (Alunno-Bruscia \& Sainte-Marie 1998, Comeau et al. 1998, Orensanz et al. 2007, Burmeister \& Sainte-Marie 2010). The reasons for high variability in terminal size are not fully understood, but the broad size range of both sexes implies that some biotic or abiotic factors affect snow crab growth and maturation (Foyle et al. 1989).

Growth in snow crabs, as in all crustaceans, is a step-wise process between successive stages (instars) and is a function of both molting frequency and the size increase at molting (molt increment), as described by Sainte-Marie et al. (1995) for the northern Gulf of St. Lawrence (nGSL). Early benthic juveniles molt frequently until instar VI, at about $20 \mathrm{~mm}$ CW, following which molting occurs on a near annual schedule during spring. At around this size, the first event in sexual maturation of females (i.e. the prepuberty molt) marks the onset of ovary development, and is accompanied by a decrease in molt increment and a large increase in relative growth of the abdomen (Alunno-Bruscia \& Sainte-Marie 1998). The first event in sexual maturation of males is the puberty (or 'adolescent') molt, which occurs at about 37 to $38 \mathrm{~mm} \mathrm{CW}$ and marks the onset of testis/vas deferens development and maturation; this molt is accompanied by a decrease in the molt increment and a modest increase in chela relative growth (Sainte-Marie et al. 1995, Comeau et al. 1998). The decrease in growth rate, reflected in the molt increment, is thus similar between the 2 sexes at the first 'critical' molt, but females initiate maturation about 2 instars before males. The second major event in maturation is the terminal molt (also the pubertal molt in females), which causes a large proportional decrease in carapace molt increment in females. The terminal ('adult') molt of males is associated with only a small proportional decrease in carapace molt increment but a large increase in chela relative growth (SainteMarie et al. 1995, Comeau et al. 1998, Hébert et al. 2002).

Males in the nGSL achieve the minimum legal size and recruit to the exploitable biomass at instar XII and about 8.7 years of post-larval age (Sainte-Marie et al. 1995). Some males may continue to molt to instar XII at about 10.7 years of age. Males on annual molting schedules are known to fail to molt in any single year or for 2 consecutive years (Sainte-Marie et al. 1995, Hebert et al. 2002). These 'skip-molters' are identified as immature crabs or adolescent males with relatively old and discolored carapaces. Crabs of both sexes may live about 5 to $7 \mathrm{yr}$ following the terminal molt, during which time the carapace ages and becomes progressively fouled and ultimately deteriorates. Snow crabs, and especially males, may undertake extensive migrations (Biron et al. 2008), including an ontogenic size-related migration (Lovrich et al. 1995, Dawe \& Colbourne 2002) and seasonal breeding migrations (Taylor et al. 1985, Maynard \& Webber 1987, O'Halloran \& O'Dor 1988),

Molting frequency (and age-at-instar) is believed to be much more variable than the molt increment (and size-at-instar) in snow crabs (Orensanz et al. 2007). Therefore, the principal mechanism creating variation in terminal size of snow crabs, as in other majid and oregoniid crabs (Hines 1989, Hartnoll et al. 1993), is believed to be the number of instars achieved (molts experienced) before terminal molt. While several extrinsic (and intrinsic) factors may be influential in regulating size-at-terminal molt (Elner \& Beninger 1992, Sainte-Marie et al. 2008), recent studies indicate that temperature is the most important factor. Orensanz et al. (2007) found that a spatial cline in mature female size in the eastern Bering Sea (EBS) was directly related to ambient bottom temperature, while Burmeister \& Sainte-Marie (2010) similarly found that spatial variation of mean size of mature females and adult males in isolated West Greenland fjords was a direct function of temperature. Regional differences in minimum size of adult males in the northern Gulf of St. Lawrence was also directly related to temperature (Sainte-Marie et al. 2008)

Improving the understanding of how temperature conditions the size-at-terminal molt has important fishery management implications, particularly under the current scenario of a changing ocean climate. However, there is considerable uncertainty regarding processes involved as there have been limited studies conducted on this subject. Very limited information is available from the northwest Atlantic (Sainte-Marie et al. 2008). Most studies have focused only on females from the EBS (Orensanz et al. 2007, Ernst et al. 2012) with only a single study (from West Greenland) including males (Burmeister \& Sainte-Marie 2010). All these studies have been based on associations of size metrics with mean temperature.

Some recent studies have hypothesized that variability in terminal size is primarily a function of conditioning by temperature during early ontogeny (Orensanz et al. 2007, Sainte-Marie et al. 2008, Burmeister \& Sainte-Marie 2010), with high temperatures promoting increased molt frequency at early post-settlement stages before the onset on an annual molting schedule at instar VI (about $20 \mathrm{~mm}$ premolt CW and 2.3 years 
post-settlement age (Sainte-Marie et al. 1995). Assuming that terminal molt occurs at a fixed age (Orensanz et al. 2007, Burmeister \& Sainte-Marie 2010), this would result in a higher instar-at-age and ultimately larger size-at-terminal molt at high temperatures than at low temperatures. This hypothesis, developed for females in the EBS, was based in part on the observation that skip-molting in EBS females was negligible (Orensanz et al. 2007). While variable molting frequency only during early post-settlement stages may account for variation in terminal size of females, it cannot account for the much greater range in terminal size of males. A more recent study of EBS females (Ernst et al. 2012) asserts that the terminal molt does not occur at a fixed age, but rather terminal size is related to age-at-maturity, with females terminally molting over an absolute range of about 5 years of age.

In this, the first comprehensive study from Canadian waters, we assume that common principles apply between the sexes. Accordingly, we hypothesize that size-at-terminal molt is conditioned by temperature over a variable number of instars and intermolt periods leading up to the terminal molt. We address this hypothesis by modeling size-at-terminal molt as a function of temperature and compare between the sexes for each of 2 segregated Canadian fishery areas. We also describe and invoke the effects of temperature on molting frequency to help explain the effects of temperature on size-at-terminal molt.
Our study addresses the possible applicability of existing hypotheses to explain relationships and trends generated from the results. We go on to develop alternative hypotheses to explain the trends observed and address the implications of these findings to mortality and fishery issues, including recruitment and yield per recruit.

\section{MATERIALS AND METHODS}

\section{Bottom trawl surveys}

Data on near-bottom temperature and snow crab biological characteristics on the southern Newfoundland Shelf (NL) were acquired from multi-species spring bottom trawl surveys on the Grand Bank and St. Pierre Bank (Fig. 1). Depth stratified multi-species surveys (Doubleday 1981) utilizing a Campelen 1800 shrimp trawl (McCallum \& Walsh, 1996, Walsh \& McCallum, 1996) were conducted each spring from 1999 to 2010. The Campelen 1800 survey trawl is a small-meshed $(80,60$ and $44 \mathrm{~mm})$ shrimp trawl that is fitted with a $12.7 \mathrm{~mm}$ mesh codend liner. It has an average wing spread ranging from 15 to $18 \mathrm{~m}$ and an average vertical opening of 4 to $5 \mathrm{~m}$. It has rockhopper footgear featuring $355 \mathrm{~mm}$ diameter rubber disks spaced at $200 \mathrm{~mm}$ intervals along the $19.6 \mathrm{~m}$ footrope. Survey tows, executed throughout the diel

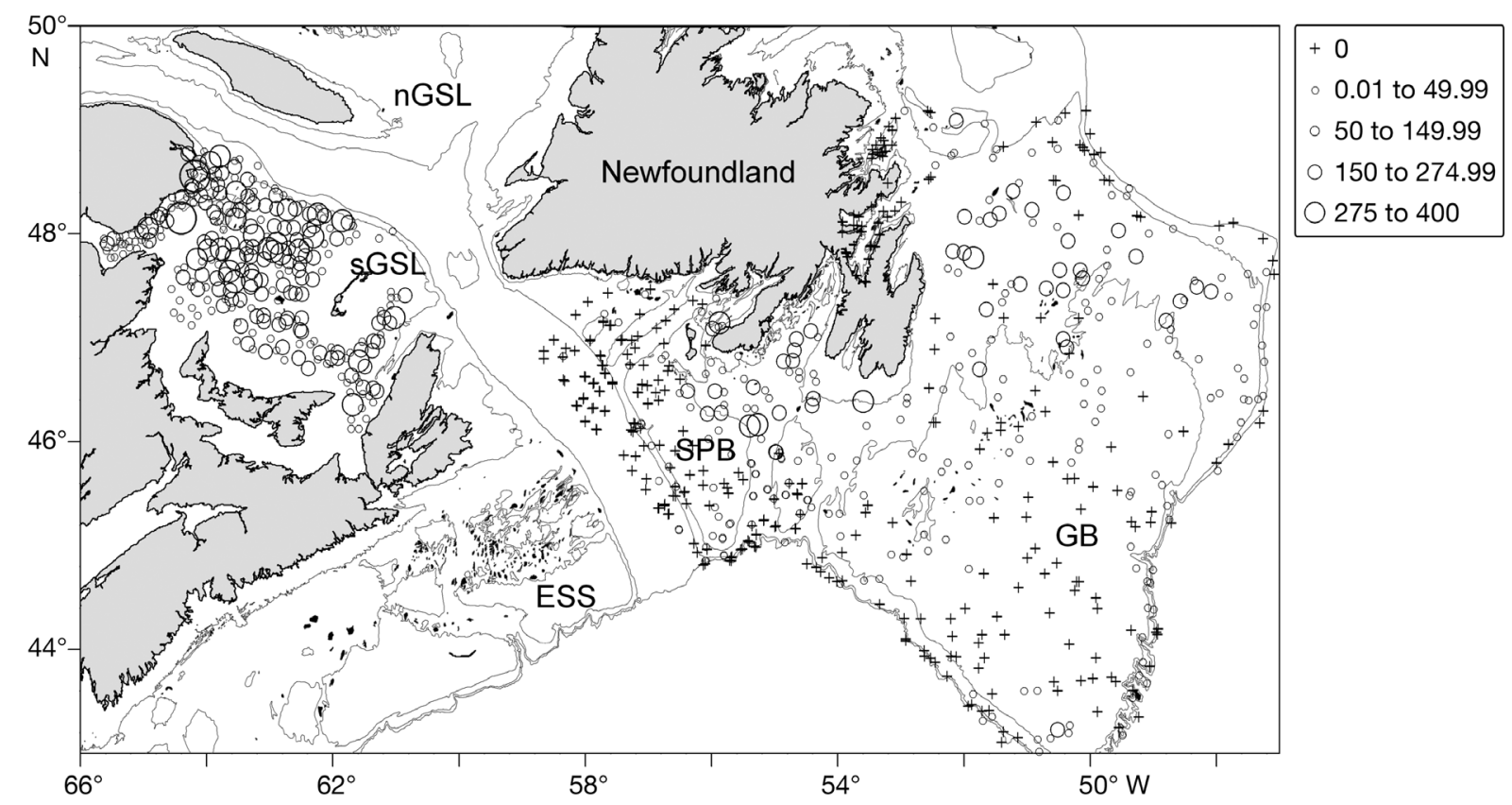

Fig. 1. Distribution of survey sets and snow crab catch rates from the 2005 surveys on the southern Newfoundland shelf and the southern Gulf of St. Lawrence: nGSL, northern Gulf of St. Lawrence; sGSL, southern Gulf of St. Lawrence; ESS, Eastern Scotian Shelf; SPB, St. Pierre Bank; GB, Grand Bank 
cycle at depths of about 50 to $1500 \mathrm{~m}$, were standardized to 15 min duration at a tow speed of 3.0 knots. A conductivity, temperature, and depth (CTD) sensor was mounted on the trawl head rope, and a SCANMAR acoustic net monitoring system was used to monitor trawl performance at each station. Unsuccessful tows were repeated at the same or alternate stations. The capture efficiency of snow crabs by this survey trawl is generally poor, especially for small crabs on hard substrates (Dawe et al. 2010). The surveys normally occurred from April to June, but extended into July in some years. The annual coverage of survey strata was variable, with inshore strata and strata deeper than $750 \mathrm{~m}$ along the slope edges not surveyed in all years, including most recent years.

In the southern Gulf of St. Lawrence, the annual snow crab post-fishing season trawl survey (19882009) has been conducted from July to October since 1988 except for 1996. The survey area includes all areas between the $36 \mathrm{~m}$ (20 fathoms) and $365 \mathrm{~m}$ (200 fathoms) isobaths. The total number of trawl stations has been increased from 155 during 1988 to 2004 to 355 in more recent years (Hébert et al. 2011). A Bigouden Nephrops bottom trawl, originally developed for Norway lobster fisheries in France (Conan et al. 1994) was used (20 m opening with a $27.3 \mathrm{~m}$ foot rope and $50 \mathrm{~mm}$ mesh in the codend). Tow duration varied between 4 and $6 \mathrm{~min}$ at a target speed of 2 knots, depending on the depth, current speed and substrate type. The horizontal opening of the trawl was measured every $4 \mathrm{~s}$ with the Netmind (Northstar Technical) distance sensors. All stations were trawled during daylight hours.

\section{Biological sampling}

Survey catches from both areas were sorted by species and enumerated at sea. Snow crabs were fully sampled in the sGSL, and either fully- or subsampled at NL based upon magnitude of the catch. Data were collected on sex, size, shell condition, maturity stage (females) and chela allometery (males). Both sexes were measured for carapace width (CW, to nearest $0.1 \mathrm{~mm}$ ) using vernier calipers. Females were categorized as mature versus immature based on morphometry of the abdomen, while males were sampled for chela height $(\mathrm{CH}$, to nearest $0.1 \mathrm{~mm})$, which was subsequently used in relation to $\mathrm{CW}$ to segregate adolescents from adults (Dawe et al. 2011 for NL, Hébert et al. 2011 for sGSL). For both sexes, shell condition was subjectively assigned to one of 5 categories ranging from soft-shelled to very-old shelled (see Table 1), reflecting time elapsed since molting (Dawe et al. 2011 for NL, Hébert et al. 2011 for the sGSL).

\section{Data analysis}

The annual distribution of bottom temperature was mapped and kriged (with Surfer 8, Golden Software USA) for both survey areas. We chose 2005 for presentation of near-bottom temperatures as the surveys were spatially almost fully complete in both areas during that year, providing comprehensive broadscale views. The thermal regime was about average for sGSL in 2005, but was warmer than average for NL. The total survey catch of snow crabs by sex, size, and temperature was plotted and compared to determine the thermal distribution of males and females in each area. We partitioned bottom temperature among $1^{\circ} \mathrm{C}$ bins with each temperature representing the midpoint of each grouping. For example, the $1^{\circ} \mathrm{C}$ temperature bin was comprised of temperatures ranging from 0.5 to $1.49^{\circ} \mathrm{C}$. Crabs associated with each temperature bin were grouped over $3 \mathrm{~mm} \mathrm{CW}$ intervals by sex, year, and area. As with temperature, size groupings were represented by the midpoint. Crabs were then pooled over all survey years for each temperature bin by sex and area. All sizes of females were included in the analysis, but males were limited to those larger than $50 \mathrm{~mm} \mathrm{CW}$, as the regression model used to segregate adolescents from adults in the NL region was not reliable for smaller sizes (Dawe et al. 1997, 2011). Males with obviously deformed or regenerated chelae were rejected.

We modeled the proportion of all new-shelled crabs that were terminally molted on carapace width by temperature bin, sex and area. Focusing on newshelled (soft + new hard-shelled) crabs allowed us to best address our hypothesis that size-at-terminal molt is conditioned by water temperature throughout the instars and intermolt periods leading up to the terminal molt. This assumes that capture temperature reflects prevailing temperature conditions during the most recent inter-molt interval. We realize that this assumption is tenuous due to potential effects of changes in thermal regime and crab movement in the interval between terminal molt and capture. Crab movement in particular likely partially masks the true association of terminal size with premolt thermal regime. However, we assume that this association, although likely weakened, is maintained due to some degree of broad-scale spatiotemporal consistency of the thermal regime in each area. 
In both areas, initial analyses revealed that logistic models produced the best fits to temperature-specific size-at-maturity distributions for females, while sixth-order polynomial regression models produced better fits to the corresponding male data. To determine the effect of temperature on size at maturity, we used these logistic and polynomial regression models to produce temperature-specific percent mature at size ogives for each area to compare the sizes at which $50 \%$ of females were mature and $50 \%$ of males were adult (mat50s).

To further investigate whether terminal size is conditioned during early life versus during more recent intermolt periods leading up to the terminal molt, we calculated mean sizes of new-shelled and old-shelled crabs by temperature bin for both mature females and adult males (both terminally molted). Linear regression models were applied to the mean size on temperature data, and regression slopes were compared between shell categories (ANCOVA, SAS 9.2) by sex and area. It was hypothesized that regression slopes would be steeper for new-shelled (most recent terminal molters) than for old-shelled (those terminally molted more than one year before capture) mature females and adult males, indicating conditioning by temperature, with new-shelled crabs remaining closer than old-shelled crabs, in time and space, to the thermal regime at which they most recently molted. New-shelled crabs included those classed as soft and new-hard shelled (see Table 1), whereas old-shelled crabs included those classed as intermediate, old, and very-old shelled from the surveys, and therefore had not molted for more than one year. A few terminally molted adult males may have been misclassified as adolescent due to undetected regeneration of chelae, but this is at a negligible level of less than $0.1 \%$ of total crabs sampled (M. Hébert pers. comm.).

The effects of physical and biological variables on the frequency of skip-molting was examined by modeling the proportion of non-terminally-molted crabs (immature crabs plus adolescent males) that had not molted during the most recent molting season on size, by area, sex and temperature bin. All immature and adolescent crabs larger than about $20 \mathrm{~mm} \mathrm{CW}$ are scheduled to molt annually during spring. Therefore, those with new carapaces during our survey periods represented crabs that molted during the most recent spring molting season. Skip-molters were defined as immature and adolescent crabs with other than new carapaces as described above. Logistic models were applied to the data for proportion skip-molting on carapace width by area, sex, and temperature bin. The significance of the effects of explanatory variables on proportion skip molting was determined, for males only, using a multiple regression model (ANCOVA, SAS 9.2). Size represented the continuous covariate in the logistic regression analysis, grouped into $3 \mathrm{~mm}$ increments. Area and temperature were treated as class variables, with temperature grouped into $1^{\circ} \mathrm{C}$ bins ranging from $-1^{\circ} \mathrm{C}$ to $4^{\circ} \mathrm{C}$.

\section{RESULTS}

\section{Thermal regime and snow crab distribution}

Both areas are characterized by a cold thermal regime, with bottom temperatures ranging from -1 to $6^{\circ} \mathrm{C}$ (Fig. 2). Virtually no crabs were caught within the very limited area $>4^{\circ} \mathrm{C}$. The sGSL represented the more homogenous area with respect to both bathymetry and thermal regime, characterized by a

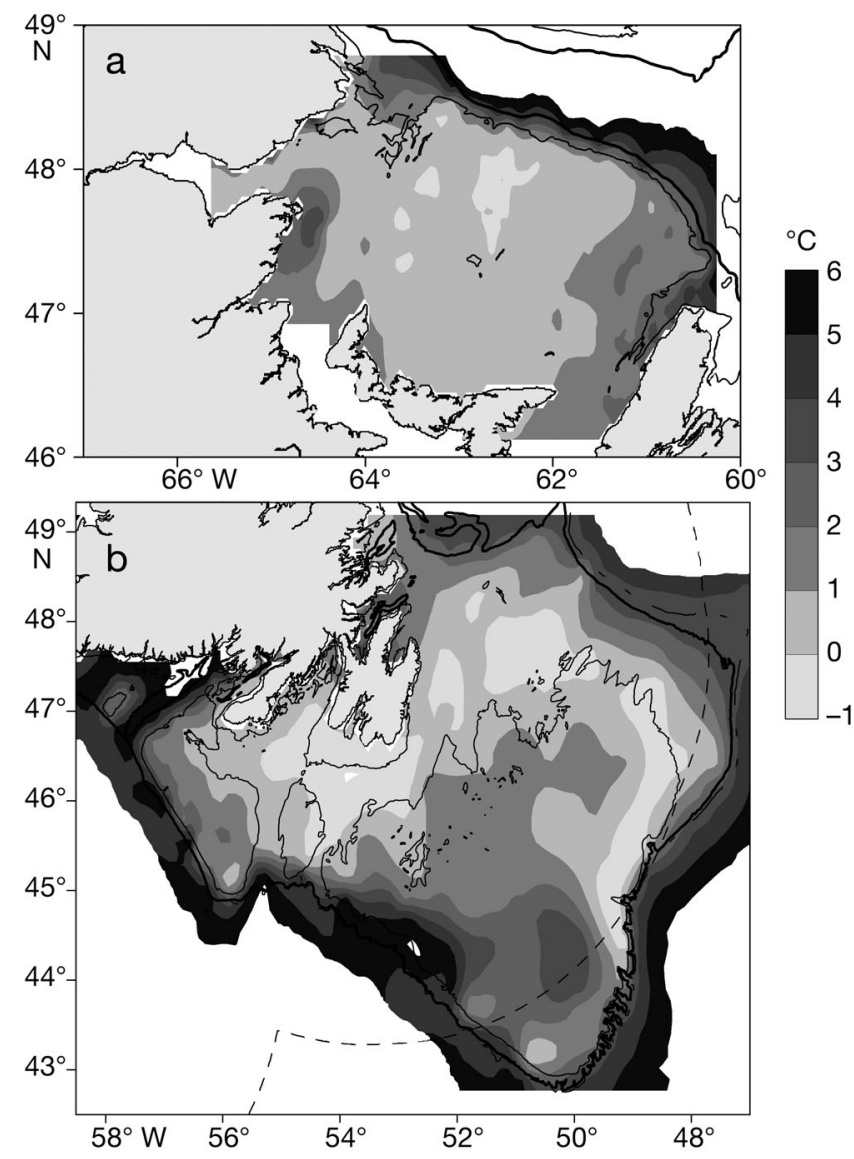

Fig. 2. Example of near-bottom temperature distribution in (a) the southern Gulf of St. Lawrence (summer 2005) and (b) the southern Newfoundland shelf (spring 2005). The dashed line represents the boundary of Canada's $200 \mathrm{n}$ mile exclusive fishery zone 
central pool of mostly $0^{\circ} \mathrm{C}$ water surrounded by smaller areas of $1^{\circ} \mathrm{C}$ on the periphery. The NL shelf was generally colder, particularly along the northern portion where cold $\left(-1\right.$ to $\left.0^{\circ} \mathrm{C}\right)$ water was common. Sub-zero temperatures were broadly distributed on the NL shelf, even in 2005, a relatively warm year, whereas they were virtually absent in the sGSL in 2005 within a more typical thermal regime. In both areas the greatest depths down over the slope edges were characterized by warmest water of about 4 to $6^{\circ} \mathrm{C}$. The spatial extent of temperature bins other than 0 and $1^{\circ} \mathrm{C}$ were particularly limited within the sGSL survey area.

Total catch by temperature bin for both sexes (Fig. 3) generally reflected variation in the spatial extent of those temperature intervals (Fig. 2). The majority of females of all sizes captured in spring NL

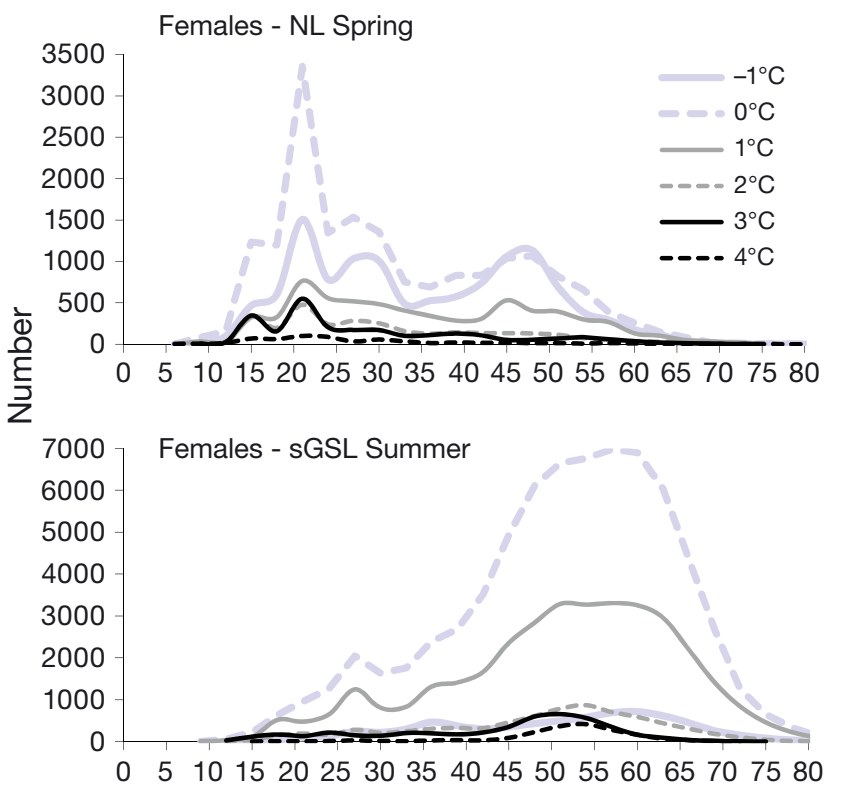

were taken from -1 and $0^{\circ} \mathrm{C}$ waters, with the catch generally decreasing progressively with temperatures above $0^{\circ} \mathrm{C}$ (Fig. 3). With a primary mode at 55 to $60 \mathrm{~mm} \mathrm{CW}$, the sGSL females were on average much larger than those captured at NL, despite increasing capture efficiency with size by the NL survey trawl (Dawe et al. 2010). Most sGSL females of all sizes were taken at 0 and $1^{\circ} \mathrm{C}$, (mainly at $0^{\circ} \mathrm{C}$ ), with relatively few females found at other temperatures. The largest catch of males across the entire size range at NL was at $0^{\circ} \mathrm{C}$, with modal groups at smallest (about 15 to $40 \mathrm{~mm} \mathrm{CW}$ ) and largest (70 to $120 \mathrm{~mm} \mathrm{CW}$ ) sizes (Fig. 3). Lowest catches, primarily of largest males (about 80 to $120 \mathrm{~mm} \mathrm{CW}$ ) were at highest temperatures $\left(2\right.$ to $\left.4^{\circ} \mathrm{C}\right)$. As with females, the majority of the sGSL males of all sizes were taken from 0 and $1^{\circ} \mathrm{C}$ areas (mainly at $0^{\circ} \mathrm{C}$ ).
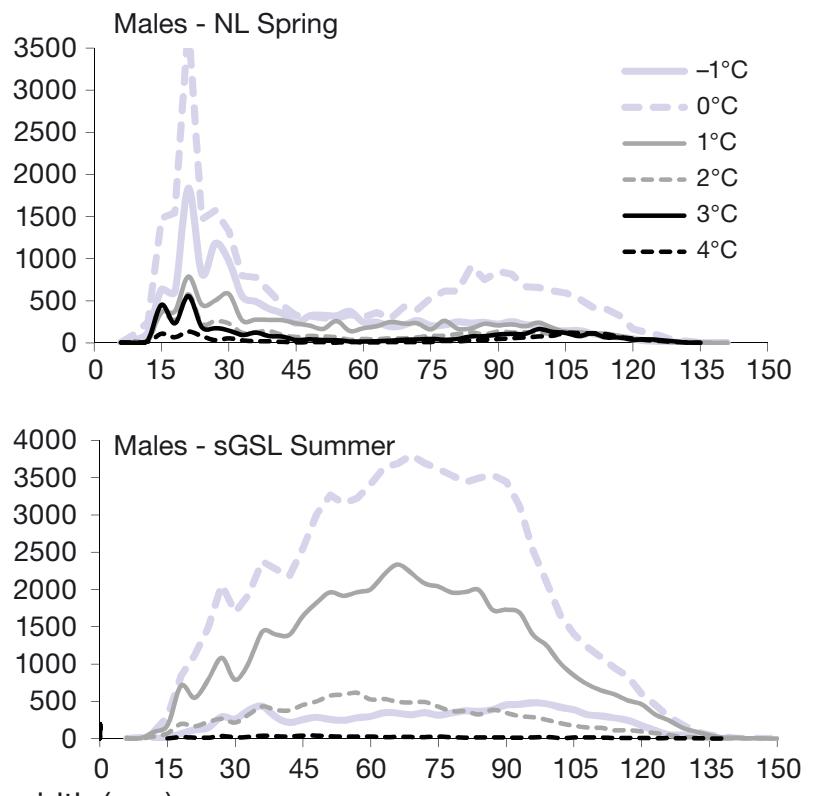

Fig. 3. Chionoecetes opilio. Sample size (number) vs. carapace width by sex and temperature bin from surveys on the southern Newfoundland shelf (NL, 1999-2010) and the southern Gulf of St. Lawrence (sGSL, 1988-2009). All shell conditions and maturities are pooled

Table 1. Chionoecetes opilio. Snow crab sample size (percentage in parentheses) by sex and reproductive stage from surveys partitioned by shell condition. NL: southern Newfoundland shelf; sGSL: southern Gulf of St. Lawrence

\begin{tabular}{|c|c|c|c|c|c|c|c|c|}
\hline & & & Soft & New & Intermediate & Old & Very old & Total \\
\hline \multirow[t]{4}{*}{ NL } & \multirow[t]{2}{*}{ M } & Adolescent & $2611(5.8)$ & 40015 (88.7) & $2133(4.7)$ & $338(0.7)$ & $29(0.1)$ & $45125(100.0)$ \\
\hline & & Adult & 1955 (15.3) & $4490(35.2)$ & 4197 (32.9) & $1971(15.5)$ & $129(1.0)$ & $12743(100.0)$ \\
\hline & \multirow[t]{2}{*}{$\mathrm{F}$} & Immature & $511(1.6)$ & 31419 (98.1) & $46(0.1)$ & $43(0.1)$ & $2(0.0)$ & $32021(100.0)$ \\
\hline & & Mature & 665 (5.3) & 4751 (38.2) & $2206(17.7)$ & $4247(34.1)$ & $577(4.6)$ & $12446(100.0)$ \\
\hline \multirow[t]{4}{*}{ sGSL } & \multirow[t]{2}{*}{$\mathrm{M}$} & Adolescent & $96168(83.7)$ & $5062(4.4)$ & $13083(11.4)$ & $424(0.4)$ & $199(0.2)$ & $114936(100.0$ \\
\hline & & Adult & 17784 (34.6) & $8712(17.0)$ & $15079(29.4)$ & 6467 (12.6) & $3283(6.4)$ & $51325(100.0)$ \\
\hline & \multirow[t]{2}{*}{$\mathrm{F}$} & Immature & 46086 (98.8) & $145(0.3)$ & $172(0.4)$ & $231(0.5)$ & $28(0.1)$ & $46662(100.0)$ \\
\hline & & Mature & $157(0.2)$ & $19855(24.5)$ & $28773(35.5)$ & $26606(32.8)$ & $5662(7.0)$ & $81053(100.0)$ \\
\hline
\end{tabular}


The molting history of snow crabs sampled was similar between the areas in most respects (Table 1). Most of the crabs sampled in both areas were newshelled (soft + new hard-shelled). This was especially true for non-terminally molted crabs, with newshelled males comprising 88 and $95 \%$ of all immature + adolescent males in the sGSL and NL, respectively, and with new-shelled females comprising more than $99 \%$ of all immature females in both areas. Interestingly, most of the new-shelled crabs from the sGSL were soft-shelled, whereas most of those from NL were new hard-shelled. For example, $84 \%$ of immature + adolescent males and $99 \%$ of immature females from the sGSL were soft-shelled, whereas only 6 and $2 \%$, respectively, from NL were soft-shelled. This indicates that most of the nonterminally molted new-shelled crabs from the sGSL summer-fall survey had molted during the immediately past spring, whereas most of those from the spring NL survey last molted almost a year earlier and were yet to molt during the current spring. Old shelled non-terminally molted crabs (old + very old) were uncommon, at $<1 \%$, in both areas (Table 1 ).

\section{Size-at-terminal molt}

For new-shelled females, logistic regression models produced very tight fits to the temperaturespecific percent mature on size data by area (Fig. 4). However, there was a tendency for the relationships to erode at highest temperatures, most evident at 3 and $4^{\circ} \mathrm{C}$ in both areas. This reflects the limited spatial distribution of such high temperatures in these areas (Fig. 2) and the consequent small sample sizes (Fig. 3). Nonetheless, these models adequately described the female data in all cases. These temperature-specific models showed that females captured in warm areas matured at larger sizes than those captured in cold areas (Fig. 5). In NL, the size-at-mat50 increased from $45 \mathrm{~mm} \mathrm{CW}$ at $-1^{\circ} \mathrm{C}$ to $59 \mathrm{~mm} \mathrm{CW}$ at $4^{\circ} \mathrm{C}$. In the sGSL size-at-mat50 increased from $48 \mathrm{~mm}$ $\mathrm{CW}$ at $-1^{\circ} \mathrm{C}$ to $62 \mathrm{~mm} \mathrm{CW}$ at $4^{\circ} \mathrm{C}$. Similarly, the probability that any molt would be the terminal molt increased with decreasing temperature, for all sizes in both areas. For example, the percent mature at $51 \mathrm{~mm} \mathrm{CW}$ increased from -1 to $4^{\circ} \mathrm{C}$ in both areas, from 12 to $84 \%$ in NL and from 12 to $62 \%$ in the sGSL.

The failure of logistic models to adequately describe the temperature-specific percent adult on size data for males reflects a much more gradual increase in the probability of terminally molting with size than in females (Fig. 6). However, polynomial regression models produced generally adequate fits to these data for males. As with females, there was a tendency for the relationships to erode at extreme temperatures in both areas. Also, the male polynomial models did not fit the NL data well at sizes smaller than about $80 \mathrm{~mm} \mathrm{CW}$. The models showed that relatively low proportions of males became adult at sizes smaller than about $90 \mathrm{~mm} \mathrm{CW}$, with the elongated lower-end tails of the models reflecting percentages of 10 to $40 \%$ terminally molted crabs in most cases. The very gradual increase in probability of terminally molting at small sizes would have been even more evident if we had been able to extend our models to the smallest sizes at which males may terminally molt. Minimum temperature-specific size-atmat50 values were $88 \mathrm{~mm} \mathrm{CW}$ in NL and $98 \mathrm{~mm} \mathrm{CW}$ in the sGSL (Fig. 7). In both areas, the models producing minimum size-at-mat50 values were associated with -1 and $0^{\circ} \mathrm{C}$ waters. The overall effect of temperature on size-at-maturity was less clear in males than in females, with relatively little separation among the temperature-specific size-at-maturity curves in both areas. Maximum temperature-specific size-at-mat50 occurred at 101 and $103 \mathrm{~mm} \mathrm{CW}$ in NL and the sGSL respectively, in both cases associated with 3 or $4^{\circ} \mathrm{C}$ waters.

Comparison of mean sizes between shell condition categories by area and sex (Fig. 8) showed that mean size was more strongly directly related to temperature for new-shelled than for old-shelled terminally molted crabs. As with the size-at-mat50 comparisons, these results were clearer for females than males, and for NL than for the sGSL. Females showed significantly steeper positive slopes of linear regression models for new-shelled than for old-shelled crabs in both areas. Similarly, males from NL also showed significantly steeper regression slopes for new-shelled than for old-shelled crabs. In fact, mean size of the sGSL old-shelled females was inversely related to temperature. Mean size of new-shelled mature females was significantly smaller than that of oldshelled mature females at the lowest temperature. Only for the sGSL males did these relationships not hold, with new-shelled mature males showing an inverse relationship with temperature.

\section{Molting frequency}

The logistic regression model did not fit the data for proportion skip-molted vs. CW for NL females (Fig. 9), whereas it provided adequate fits for sGSL 
NL spring
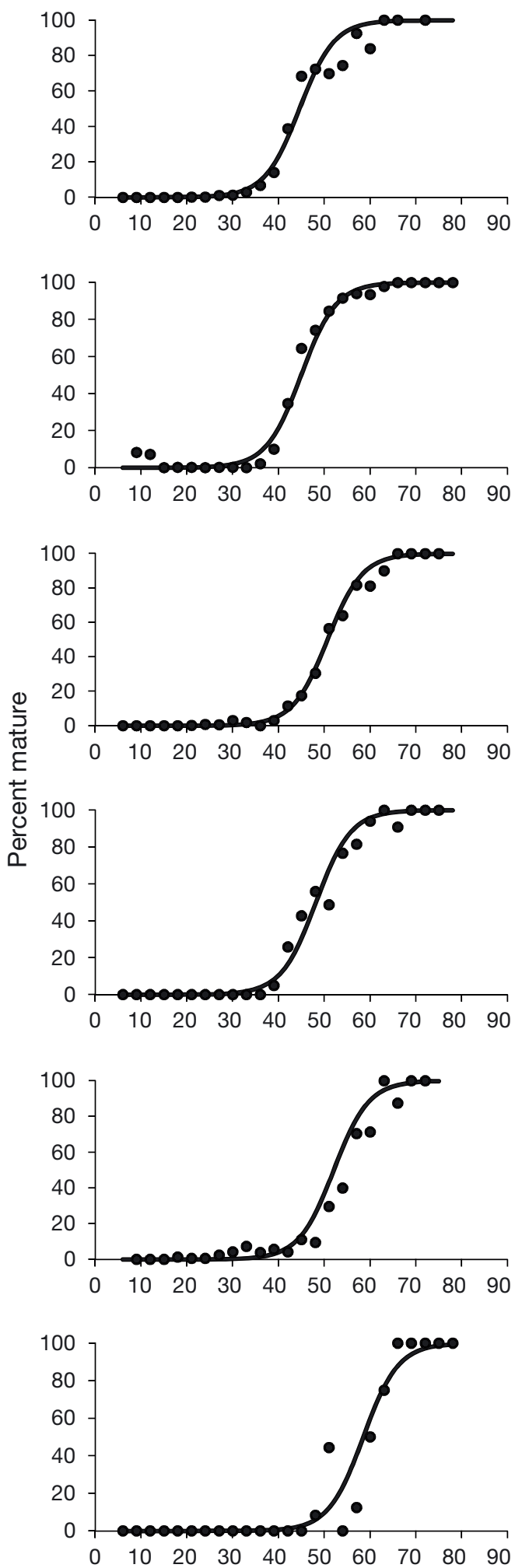

sGSL summer
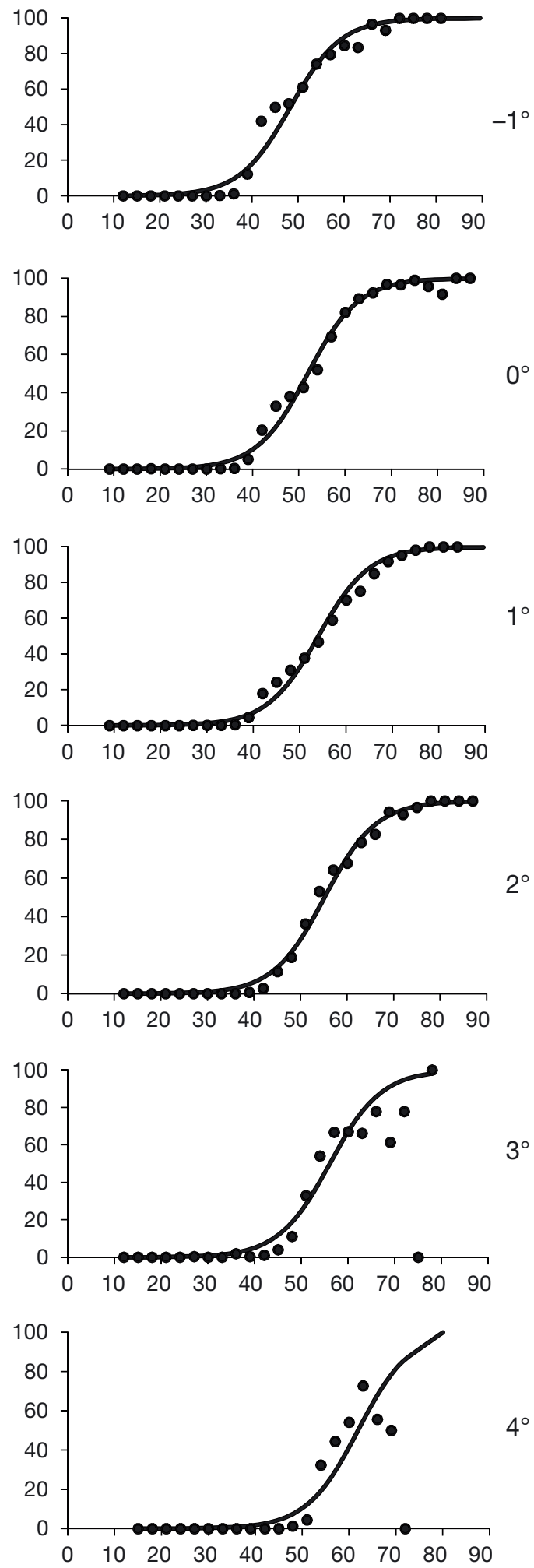

Fig. 4. Chionoecetes opilio. Application of logistic regression models to the percentage mature vs. size (carapace width), by temperature bin $\left({ }^{\circ} \mathrm{C}\right)$, for females from the southern Newfoundland shelf (NL) and the southern Gulf of St. Lawrence (sGSL) 


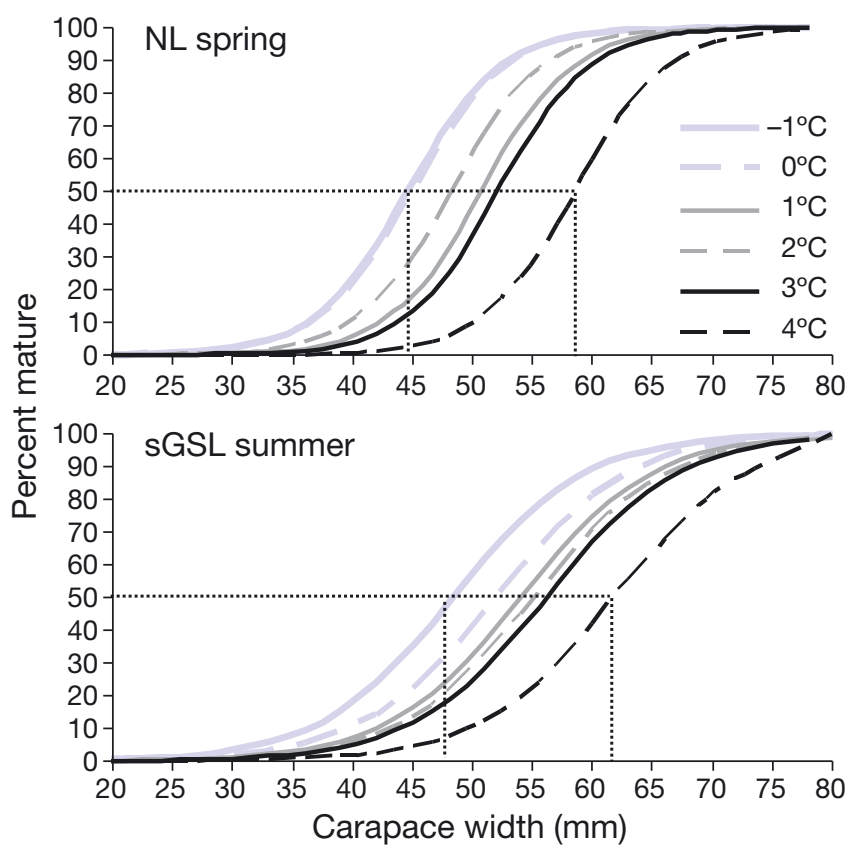

Fig. 5. Chionoecetes opilio. Temperature-specific logistic size-at-maturity models for females showing mat50 probits for the southern Newfoundland shelf (NL) and the southern Gulf of St. Lawrence (sGSL)

females and for males from both areas (Fig. 10). There was a much higher level of variability in the distribution of empirical data about the male models from NL than from sGSL (Fig. 10), reflecting greater inconsistency at NL in identifying skip molters. This inconsistency at NL is likely due largely to more variable levels of experience in assigning subjective shell condition stages by personnel sampling during NL multispecies surveys relative to those sampling during the sGSL dedicated snow crab surveys. Also, intermediate- and old-shelled skip-molters are more easily distinguished from new-shelled recent molters at sGSL (mostly soft-shelled) than at NL (mostly newhard-shelled) (Table 1). The models for males from both areas over-estimated proportion of skip-molting at largest sizes, greater than about 80 to $90 \mathrm{~mm} \mathrm{CW}$ (Fig. 10), which we attribute to effects of fishery induced mortality on legal-sized males (>95 mm CW) as well as on largest sub-legal sized males that are captured and released in the fishery. A large number, but small percentage of oldest-shelled (old + very old shelled) skip-molters (especially males) from both NL ( $0.8 \%$ of males) and sGSL $(0.6 \%$ of males) represent crabs that skipped 2 or more consecutive molts (Table 1).

Skip-molting was virtually absent in both sexes at sizes smaller than about $50 \mathrm{~mm} \mathrm{CW}$ (Figs. $9 \& 10$ ). It was common in females only in the largest immature individuals that were caught at 0 and $1^{\circ} \mathrm{C}$ in the sGSL (Fig. 9). At those temperature bins the percentage of skip-molting sGSL females increased sharply from a virtual absence at $50 \mathrm{~mm} \mathrm{CW}$ to about $50 \%$ at $70 \mathrm{~mm}$ CW, a much sharper increase than in comparablysized males from the same area and thermal regime (Fig. 10).

The multiple regression analysis (Table 2) indicated that the frequency of skip-molting in males was also directly related to size. This very highly significant effect (chi-square $=867.53, \mathrm{p}<0.0001$ ) was consistent between areas as well as across all temperature bins (Fig. 11). It increased to maxima of 57 and $58 \%$ respectively in NL and the sGSL. It ranged 22 to $58 \%$ for adolescents larger than $100 \mathrm{~mm} \mathrm{CW}$ across all temperatures and both areas. The effects of both class variables, area $(p<0.0001)$ and temperature $(\mathrm{p}=0.0019)$, were also significant as were most interactions. Skip-molting in males was overall more frequent in the sGSL than in NL. The frequency of male skip molting at the temperatures most common to both areas $\left(0\right.$ and $\left.1^{\circ} \mathrm{C}\right)$ increased more rapidly with size in the sGSL than at NL (Fig. 11), as reflected in the significant size by area interaction (Table 2).

The effect of temperature was less clear than that of size (Fig. 11), but overall the frequency of male skip molting was inversely related to temperature (chi-square $=9.61, \mathrm{p}<0.01$, Table 1 ). The interaction of temperature with size in affecting male skip molting frequency was highly significant (chi-square = $31.77, \mathrm{p}<0.0001$ ). For both areas, the highest incidence of skip molting was generally at the lowest temperatures that were most extensive in each area (ie -1 and $0^{\circ} \mathrm{C}$ at NL versus 0 and $1^{\circ} \mathrm{C}$ at sGSL), and frequency generally decreased at higher temperatures (excepting $3^{\circ} \mathrm{C}$ at NL) and the extreme low temperature at sGSL $\left(-1^{\circ} \mathrm{C}\right)$ (Fig. 11).

\section{DISCUSSION}

\section{Effects of temperature}

We confirmed that size-at-terminal molt in both sexes from NL and the sGSL is directly related to temperature, as shown in previous studies from the EBS for females (Orensanz et al. 2007) and from West Greenland for both sexes (Burmeister \& Sainte-Marie 2010). Sainte-Marie at al. (2008) reviewed the more limited information available from the nGSL that indicated such a direct effect of temperature on female terminal size (Sainte-Marie \& Gilbert 1998) and proposed that temperature may also affect termi- 
NL spring
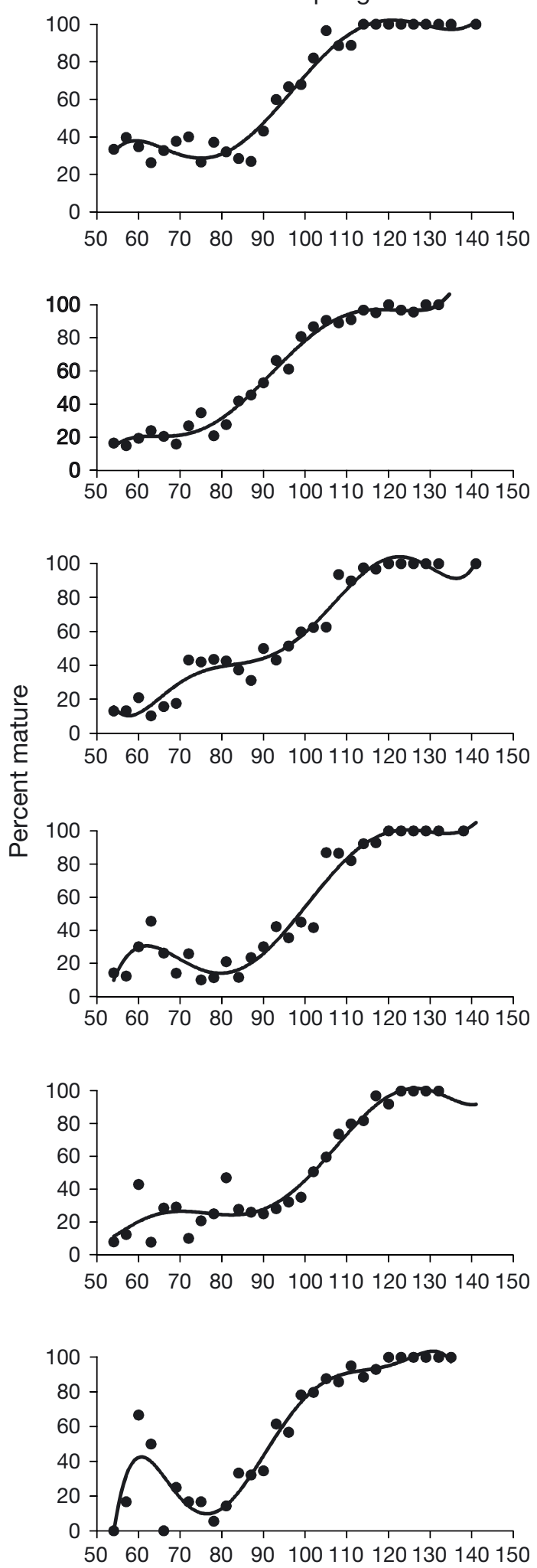

sGSL summer
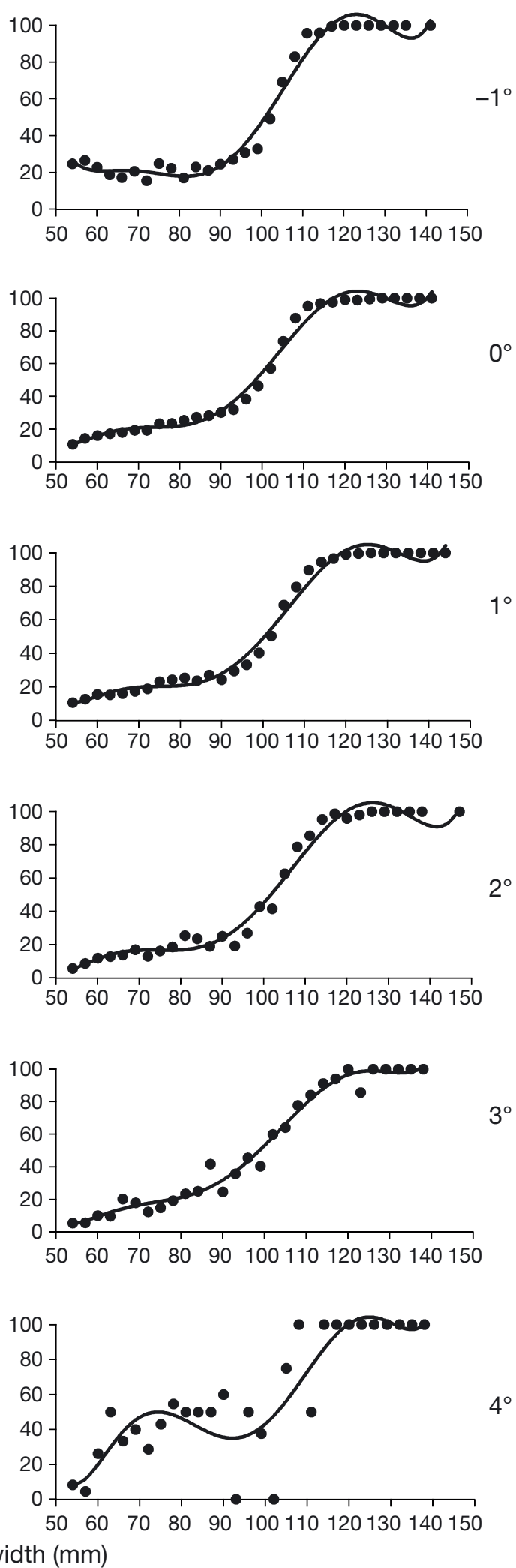

Fig. 6. Chionoecetes opilio. Application of sixth-order polynomial regression models to the percentage 'mature' (ie. adult) vs. size (carapace width), by temperature bin $\left({ }^{\circ} \mathrm{C}\right)$ for males from the southern Newfoundland shelf (NL) and the southern Gulf of 


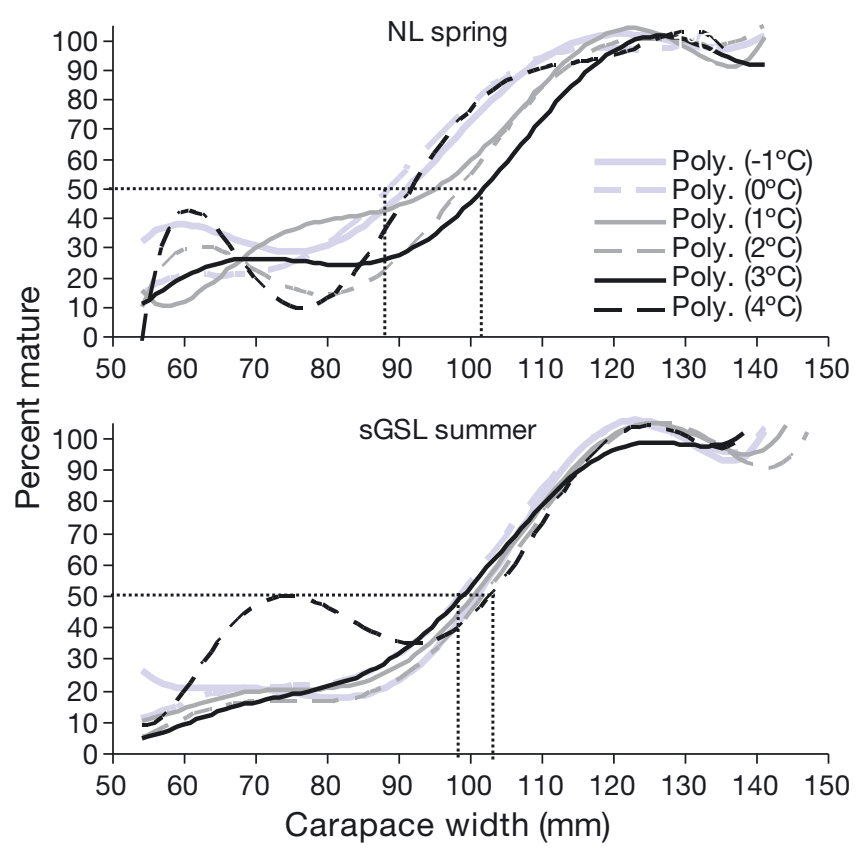

Fig. 7. Chionoecetes opilio. Temperature-specific polynomial (poly.) size-at-adulthood models for males showing mat50 probits for the southern Newfoundland shelf (NL) and the southern Gulf of St. Lawrence (sGSL)

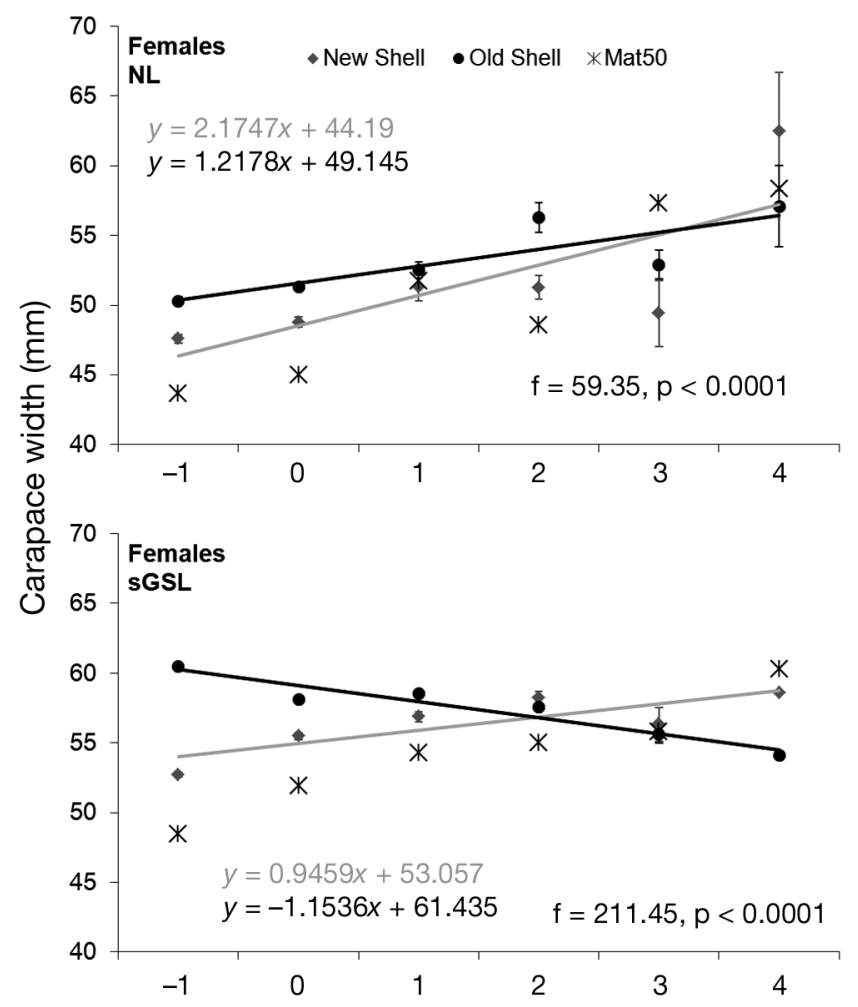

nal size of males (Alunno-Bruscia \& Sainte-Marie 1998). Those studies, based on size metrics alone, hypothesized that size-at-terminal molt is conditioned by temperature during the first 2 to 3 years of life, prior to the onset of an annual molting schedule and that age ultimately triggers the terminal molt.

We suppose this hypothesis, developed for EBS females, was based on the observation that annually molting females do not skip molts (Orensanz et al. 2007). However, our data, based on both sexes in NL and in the sGSL, show that Canadian snow crabs do skip annual molts and that the frequency of skipmolting is strongly and directly related to body size, although it is also inversely related to temperature. We found that skip-molting is negligible in both sexes at sizes smaller than about $50 \mathrm{~mm}$, such that most females achieve their terminal size without skipping a molt, as found in previous studies (Orensanz et al. 2007, Burmeister \& Sainte-Marie 2010, Ernst et al. 2012). However, many of the largest sGSL females (>50 mm CW) skipped a molt at low temperatures before terminally molting to largest sizes of about 75 to $80 \mathrm{~mm}$ CW. Accordingly, it is clear from our results that size-at-terminal molt is conditioned

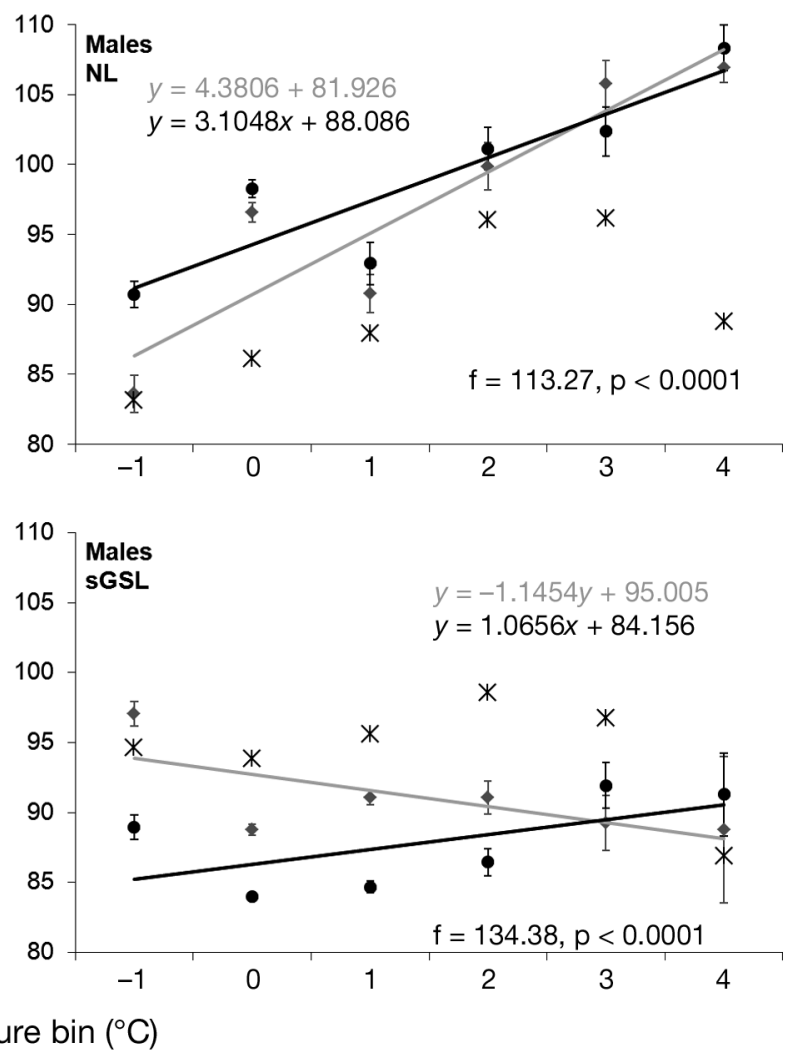

Fig. 8. Chionoecetes opilio. Mean $( \pm 2 \mathrm{SE})$ size of new-shelled and old-shelled mature females and adult males from the southern Newfoundland shelf (NL) and the southern Gulf of St. Lawrence (sGSL) with linear regression models and results of the tests of significance of differences between regression slopes (f). Sizes at $50 \%$ maturity (females) or adulthood (males) are also shown, as Mat50 for both sexes 
NL spring
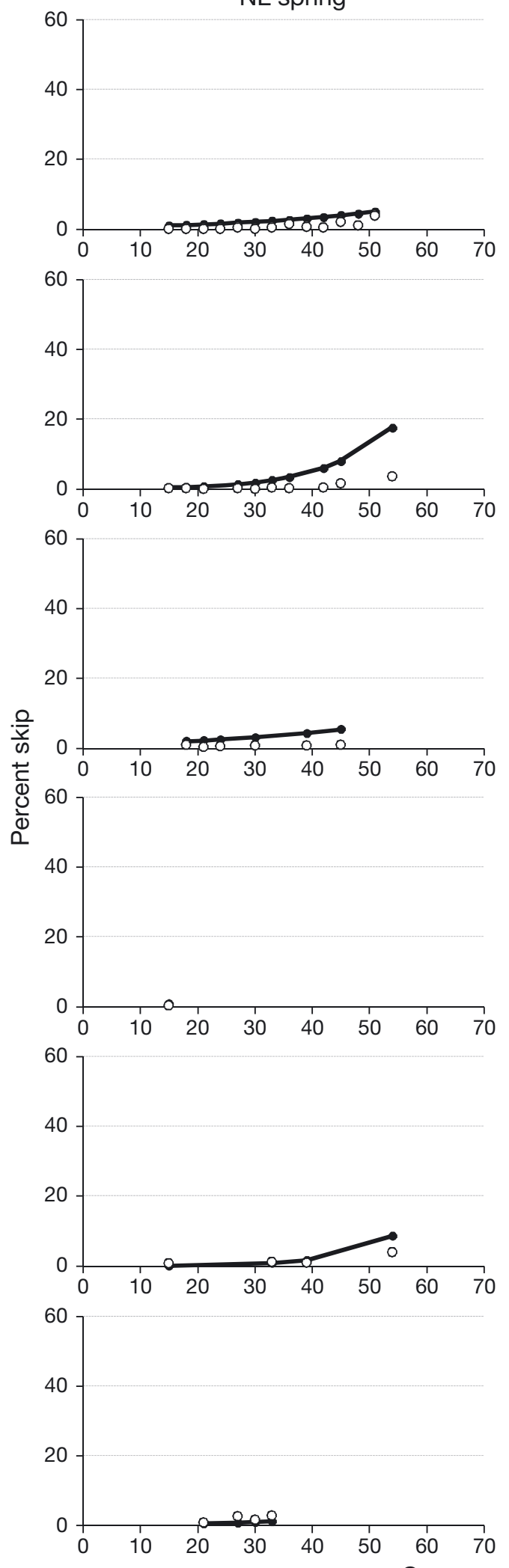
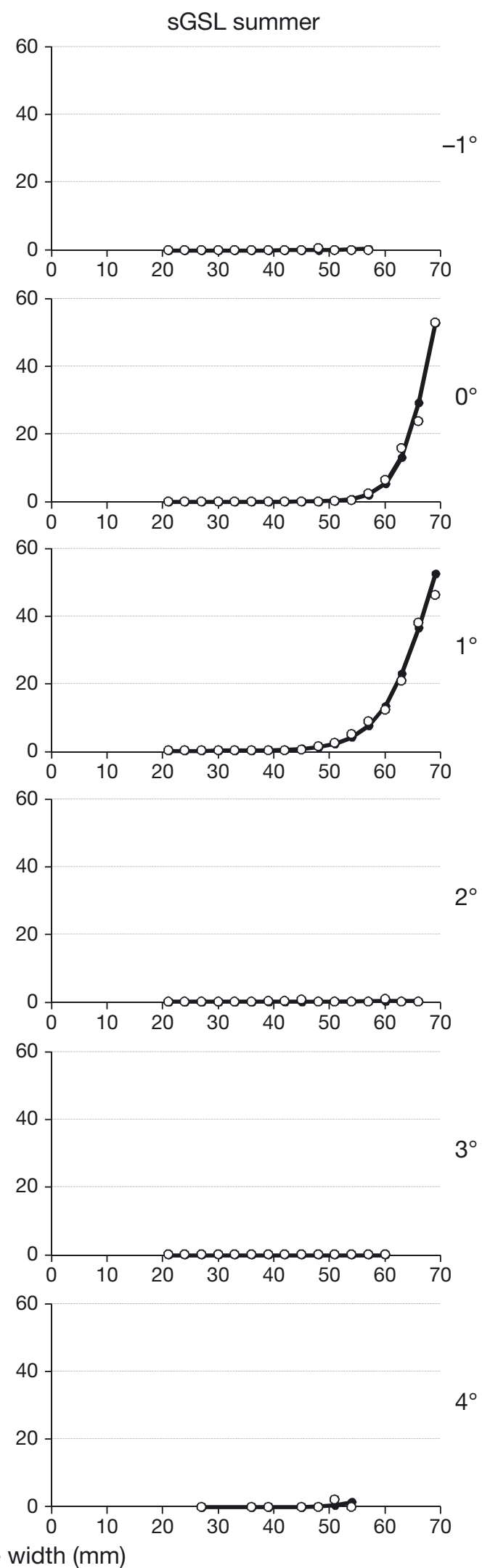

Fig. 9. Chionoecetes opilio. Logistic regression models applied to the empirical percentage skip-molting (percent skip) vs. size (carapace width), by temperature bin $\left({ }^{\circ} \mathrm{C}\right)$, for females from the southern Newfoundland shelf (NL) and the southern Gulf of St. Lawrence (sGSL). Filled circles represent predicted values; open circles represent observed values 

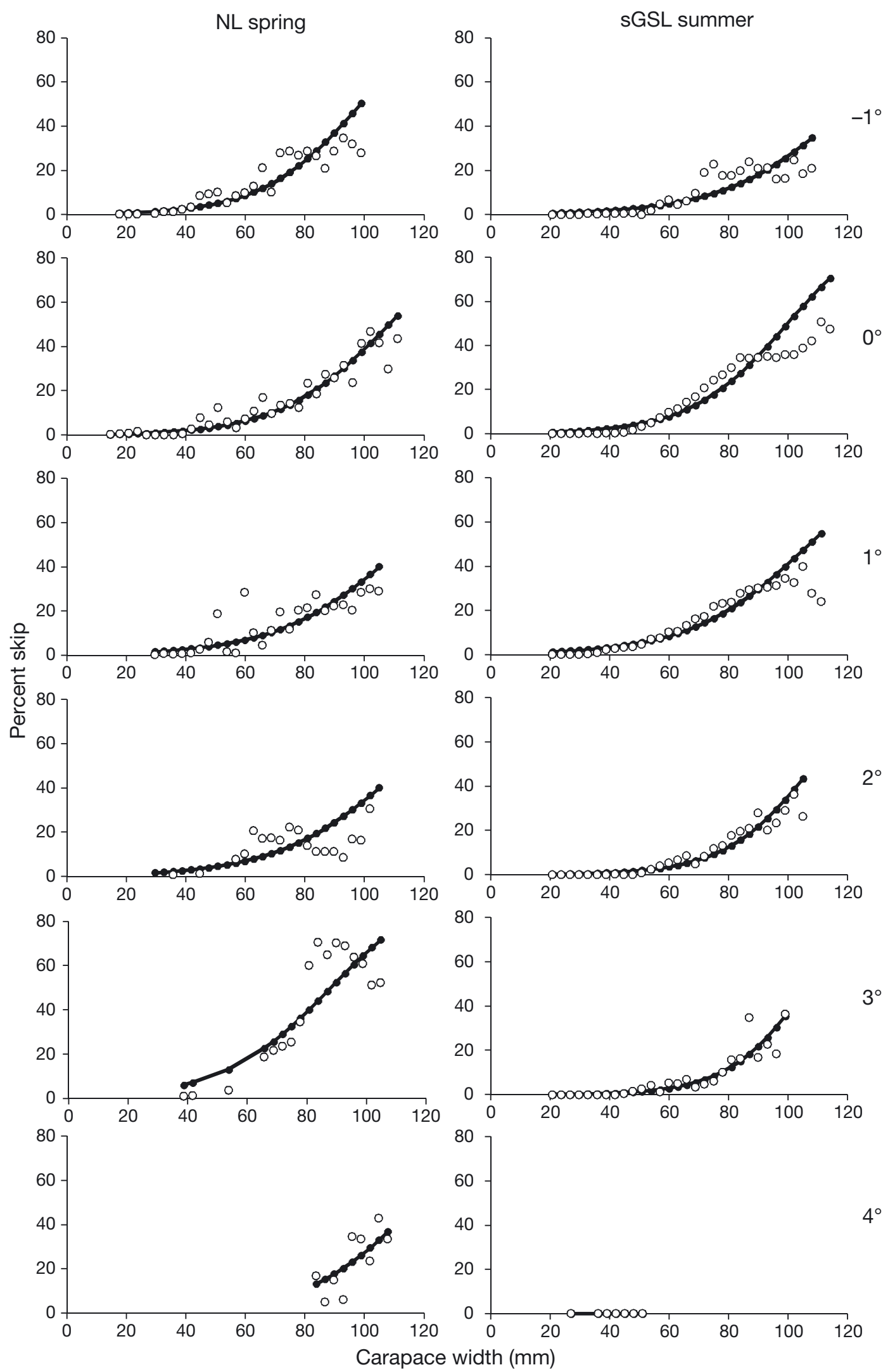

Fig. 10. Chionoecetes opilio. Logistic regression models applied to the empirical percentage skip-molting (percent skip) vs. size (carapace width), by temperature bin, for males from the southern Newfoundland shelf (NL) and the southern Gulf of St. Lawrence (sGSL). Filled circles represent predicted values; open circles represent observed values 
Table 2. Results of logistic multiple regression analysis of male snow crab percentage skip-molting on size by area and temperature bin (temp). All main effects and significant interaction effects are shown

\begin{tabular}{|c|c|c|c|c|c|c|c|}
\hline Parameter & $\mathrm{df}$ & Estimate & Standard error & \multicolumn{2}{|c|}{ Wald $95 \%$ confidence limits } & Wald chi-square & $\mathrm{p}>$ chi-square \\
\hline Intercept & 1 & -6.5205 & 0.1548 & -6.8239 & -6.2171 & 1774.31 & $<0.0001$ \\
\hline Size & 1 & 0.0616 & 0.0021 & 0.0575 & 0.0657 & 867.53 & $<0.0001$ \\
\hline Area & 1 & 0.3793 & 0.0861 & 0.2106 & 0.548 & 19.42 & $<0.0001$ \\
\hline Temp & 1 & -0.1766 & 0.057 & -0.2883 & -0.065 & 9.61 & 0.0019 \\
\hline Size $^{*}$ Area & 1 & -0.0032 & 0.0011 & -0.0054 & -0.001 & 7.87 & 0.005 \\
\hline Size $^{*}$ Temp & 1 & 0.0027 & 0.0005 & 0.0018 & 0.0037 & 31.77 & $<0.0001$ \\
\hline Area*Temp & 1 & -0.0724 & 0.0229 & -0.1173 & -0.0275 & 9.97 & 0.0016 \\
\hline
\end{tabular}

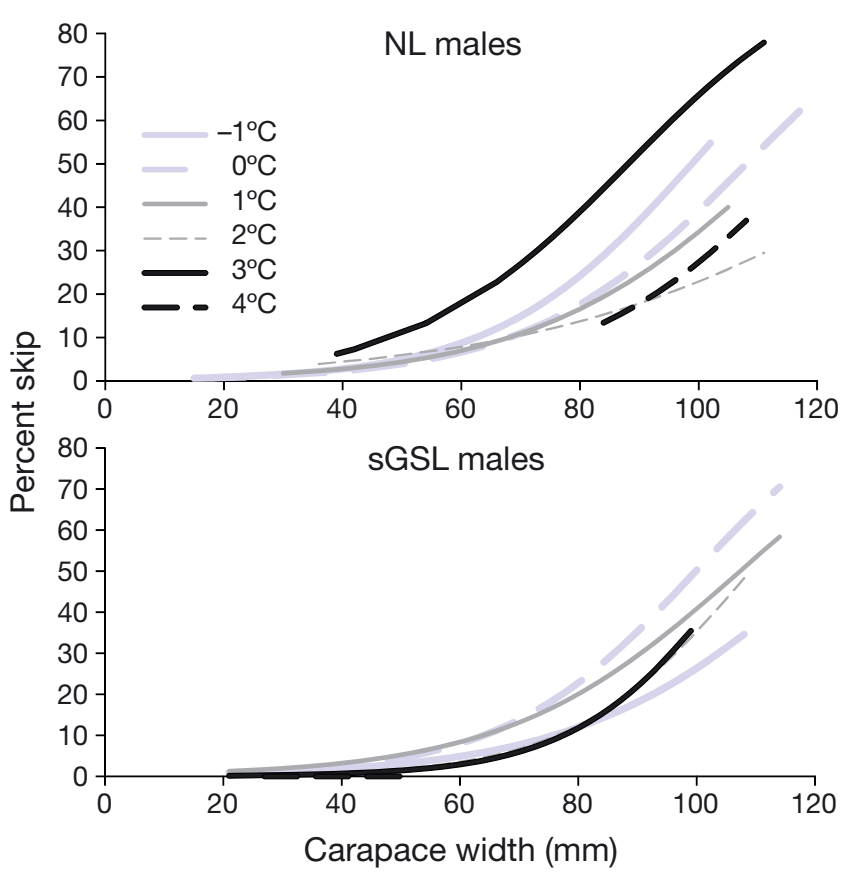

Fig. 11. Chionoecetes opilio. Comparison of male logistic regression models describing the percentage skip-molting (percent skip) vs. size (carapace width), across temperature bins for the southern Newfoundland shelf (NL) and the southern Gulf of St. Lawrence (sGSL)

by temperature throughout the life history of both sexes, including the most recent intermolt periods leading up to the terminal molt, and occurs at highly variable ages. This conclusion better accounts for the broad range in terminal size for both sexes (especially males) than does the hypothesis of conditioning only during early ontogeny and an age-related trigger (Orensanz et al. 2007, Burmeister \& Sainte-Marie 2010). It more closely agrees with Ernst et al. (2012), who concluded that terminal molt may occur over a range of about $5 \mathrm{yr}$ of age for EBS females, despite negligible skip-molting. While the size and age at terminal molt are highly variable in males, the maximum age at terminal molt is more conservative. Males that skip molts frequently and terminally molt at small size in a cold thermal regime may actually be older than larger adults that skipped fewer molts at higher temperatures. This is consistent with the observation that temperature effects at early benthic stages on subsequent recruitment to fisheries operate over a longer time interval in cold areas than in warm areas (Dawe et al. 2008).

Our study did not rely on size metrics alone, as did the earlier studies. By modeling size-at-maturity for new-shelled (recently-molted) crabs as a function of temperature we showed that conditioning of terminal size by temperature includes the most recent intermolt period. For example, we showed that at any given size, especially for females, the percentage that had recently terminally molted decreased with increasing temperature at capture. This is further supported by our comparison of mean size by shell condition. We found that mean size was more strongly directly related to temperature for newshelled than for old-shelled crabs based on differences in slopes of linear regression models.

The effects of temperature on size-at-terminal molt were consistent between the sexes, although they were clearer for females than males. This sex difference is attributed, in part, to poorer fits of size-at maturity models for males than females. Males may be influenced by sample size limitation at small sizes, as well as fishery effects at large sizes. The removal of large adult males by the fishery introduces a bias into the size-at-maturity analysis. Males also undertake more pronounced ontogenetic and seasonal migrations than do females (Ennis et al. 1990, SainteMarie \& Hazel 1992, Comeau et al. 1998, Dawe \& Colbourne 2002), such that temperature at capture may not reflect the thermal conditions throughout the past intermolt period as well as it does for females. Despite these confounding factors, it was clear that sex effects included a stronger response to temperature by females than males, as reflected by the very gradual rate of terminally molting at small male sizes. 
The relationships we found between temperature and terminal size generally agreed between study areas but were clearer for NL than for the sGSL, despite the fact that new-shelled crabs sampled during summer-fall from the sGSL (mostly soft-shelled) were more recently molted than those sampled during spring at NL (mostly new-hard-shelled) and so were sampled closer in time to the most recent molt. We attribute this apparent paradox to the much greater size of the NL than the sGSL survey area and greater heterogeneity in its bathymetric and thermal regimes. Despite crab movements and temporal change in thermal regime, crabs are more likely to remain associated with any temperature bin for a longer period at NL than at sGSL.

Several authors have offered possible explanations for skip-molting, including low physiological condition, mating success as adolescents, density-dependence, and temperature (Elner \& Beninger 1995, Comeau et al. 1998, Godbout et al. 2002, SainteMarie et al. 2008). Our results indicate that skipmolting is a function of an interaction between size and temperature, with highest rates at largest sizes and low temperatures $\left(0\right.$ and $\left.1{ }^{\circ} \mathrm{C}\right)$. Size exerting the greatest effect on skip-molting frequency is logical in that body size is constrained by an increasing energy requirement with growth. The metabolic rate of wellfed ectotherms, in general, scales as a power function of body mass (van der Meer 2006, Brose 2010) and increases exponentially with temperature (Brown et al. 2004). Skip-molting results in the ability to store somatic energy over an extended intermolt period, thereby facilitating the achievement of a threshold physiological condition necessary to successfully molt at large sizes (Godbout et al. 2002). The decrease in incidence of skip molting with increasing temperature is consistent with increasing molting frequency with temperature in crustaceans generally (Hartnoll 1982), which reflects a direct effect of temperature on metabolic rate. Paul \& Paul (2001) found that the intermolt period in Tanner crab (Chionoecetes bairdii) is inversely related to temperature, while more recently, Dutil et al. (2010) showed that in the laboratory, snow crabs molt earlier at higher than at lower temperatures.

The direct effect of temperature on snow crab metabolic rate is reflected in studies of snow crab bioenergetics (Foyle et al. 1989, Thompson \& Hawryluk 1990). Laboratory studies on relatively large (85 to $95 \mathrm{~mm} \mathrm{CW}$ ) adult male snow crabs (Foyle et al. 1989 ) indicate that food consumption increases up to $6^{\circ} \mathrm{C}$. Metabolic costs increase with temperature and overtake caloric intake at about $7^{\circ} \mathrm{C}$. An anomaly to the general effect of temperature was that growth becomes negative at very low temperatures $\left(<1^{\circ} \mathrm{C}\right)$, implying that effects of temperature on large adult males may not apply to all other life history stages. This is consistent with the observed distribution of snow crabs at NL (Dawe \& Colbourne 2002), in that smallest crabs are mostly distributed on hard substrates at shallowest depths and lowest temperatures, whereas largest males tend to be associated with soft mud substrates at greatest depths and warmest temperatures. The inverse relationship of incidence of male skip-molting with temperature is consistent with snow crab bioenergetics in that the greatest positive energy balance (digestible energy minus metabolic costs) in large adult males occurred at $4^{\circ} \mathrm{C}$ in the laboratory (Foyle et al. 1989). We feel that this can be explained by variation in habitat suitability in that foraging ability may become limiting for large crabs at low temperatures due to relatively low absolute food availability on hard substrates or increased competition associated with increase in individual growth and population biomass. The ontogenic migration of males (Dawe \& Colbourne 2002) is adaptive in that it results in distribution of large males to deep warm areas on soft substrates, where growth potential is maximized. This may also result in an improved feeding regime due to increase in absolute food availability on mud substrates and reduced density and competition.

\section{Mechanism for regulation of size-at-terminal molt}

We assume that size-at-terminal molt is regulated by principles that are generally common to both sexes. Accordingly, we offer a most plausible hypothesis for regulation of size-at-terminal molt that also accounts for the observed differences between the sexes. Crabs of both sexes, on annual molting schedules, maintain good physiological condition and rarely skip molts at sizes smaller than about $50 \mathrm{~mm}$ CW. Larger crabs have 3 options during each spring molting season; to forego the annual molt (skip molt), undertake a regular molt to remain immature-pubescent (females) or adolescent (males), or to commit to the terminal molt. Molting is highly demanding, such that crabs must commit to one of these options at least 2 to 3 mo prior to the start of actual ecdysis (Sainte-Marie et al. 1995, O'Halloran $\&$ O'Dor 1988). We hypothesize that the 'decision' to molt in both sexes is based upon achievement of some threshold physiological condition that enhances the probability of surviving the molt. The 
height of this threshold differs between the sexes and with type of molt, depending on the energetic cost of molting. The highest threshold is associated with the puberty molt of females, which is also the terminal molt, because of the cumulative high energetic cost associated with development of the ovary over several intermolt periods leading up to the terminal molt with extrusion of the first egg clutch (Alunno-Bruscia \& Sainte-Marie 1998). This is supported by the great increase in frequency of skipmolting with size that we found in largest sGSL females. The male puberty molt (to adolescence) is less costly, and least costly is the male terminal molt. These differences in hypothetical thresholds are reflected in the changes in molt increment with each type of molt (Sainte-Marie et al. 1995, 2008). Since maximum size is also constrained by energy requirement, females will commit to the terminal molt as soon as possible, especially at low temperatures. Failure to achieve the threshold physiological condition results in undertaking a molt to remain immature or (at largest immature size) skipping a molt before being forced, by size constraints, to terminally molt over the next 1 to 2 instars. Adolescent males, already sexually mature, may not commit to the terminal molt upon achieving their low physiological threshold, but rather opt to skip annual molts and undertake further adolescent molts until they are finally forced by energetic constraints at large size to undertake the terminal molt. This occurs at largest sizes within energetically-favourable warm regimes.

This proposed mechanism is consistent with life history theory in that the probability of successfully reproducing for females is maximized by terminally molting (and maturing) as early as possible. This also enhances lifetime fitness in that females surviving their first reproductive event may continue to reproduce (as multiparous females) for several years without the energetic demands of molting or (necessarily) re-mating (Elner \& Beninger 1992, Sainte-Marie et al. 2008). Conversely, males may successfully first reproduce as sexually mature adolescents, but lifetime fitness is maximized by deferring the terminal molt to very large sizes. Large adult males mate as many females as possible and most females (including virtually all multiparous females) are mated by large adults (Sainte-Marie et al. 1999, 2008). It is unlikely that smallest size at terminal molt in males is related to physiological condition alone. More likely some other density-dependent factor that enhances individual fitness is also involved, such as reproductive success as an adolescent.

\section{Implications for fisheries}

This study has important implications for fisheries. High temperatures are clearly positive from an immediate recruitment perspective. Increase in male terminal size with temperature results in a relatively large portion of a cohort achieving the minimum legal size and recruiting to fisheries. It also results in large size at recruitment in that males at high temperatures have a relatively high probability of delaying the terminal molt to sizes as large as about $115 \mathrm{~mm} \mathrm{CW}$, and molting to a maximum size of about $140 \mathrm{~mm} \mathrm{CW}$. This is reflected in larger mean size of recruited males in deeper warmer areas north of the Grand Bank and on the eastern slope of the Grand Bank than on the cold shallow shelf of the Grand Bank and St. Pierre Bank (Dawe et al. 2011). It also accounts for the very large size of recruited crabs in the warmest Atlantic Canadian fishery area on the eastern Nova Scotian Shelf (Choi \& Zisserson, 2007).

While the effects of temperature on probability of recruiting to fisheries and size at recruitment are clear, its overall effect on recruitment level is not. Our study implies that highest temperatures would promote recruitment through positive effects on both size at recruitment and proportion continuing to molt to legal-size. However, recent studies (Dawe et al. 2008, Marcello et al. 2012, this volume) indicate that production and subsequent recruitment are promoted by low temperatures during early life history. Therefore, the positive effects of low temperature on production or early survival are stronger than any potentially negative effects on growth and recruitment in later life.

Acknowledgements. We thank J.-D. Dutil (DFO, Mont-Joli, $P Q$, Canada) for helpful discussions during the early stages of this study. Thanks also go to D. Parsons (DFO, St. John's, NL, Canada) and B. Sainte-Marie (DFO, Mont-Joli, PQ, Canada) for constructive comments provided on an earlier draft of this manuscript, as well as M. Hébert (DFO, Moncton NB, Canada) for his valuable information on biological sampling. This study was conducted as part of the internationally collaborative research program ESSAS (Ecosystem Studies of Sub-arctic Seas); our thanks go to G. Hunt and K. Drinkwater, ESSAS co-chairs, and F. Mueter, co-chair of the ESSAS working group on Climate Effects at Upper Trophic Levels, for organizational support related to this study.

\section{LITERATURE CITED}

Alunno-Bruscia M, Sainte-Marie B (1998) Abdomen allometry, ovary development, and growth of female snow crab, Chionoecetes opilio (Brachyura: Majidae), in the northwestern Gulf of St. Lawrence. Can J Fish Aquat Sci 55:459-477 
Biron M, Ferron C, Moriyasu M (2008) Movement of adult male snow crab, Chionoecetes opilio, in the Southern Gulf of St. Lawrence and eastern Nova Scotia, Canada. Fish Res 91:260-270

> Brose U (2010) Body-mass constraints on foraging behaviour determine population and food-web dynamics. Funct Ecol 24:28-34

- Brown JH, Gillolly JF, Allen AP, Savage VM, West GB (2004) Toward a metabolic theory of ecology. Ecology 85: 1771-1789

Burmeister A, Sainte-Marie B (2010) Pattern and causes of a temperature-driven gradient of size at terminal molt in snow crab (Chionoecetes opilio) along West Greenland. Polar Biol 33:775-788

Choi JS, Zisserson BM (2007) An assessment of the snow crab resident on the Scotian Shelf in 2006. DFO Can Sci Advis Sec Res Doc 2007/017, Ottawa

- Comeau M, Conan GY, Maynou F, Robichaud G, Therriault J, Starr M (1998) Growth, spatial distribution, and abundance of benthic stages of the snow crab (Chionoecetes opilio) in Bonne Bay, Newfoundland, Canada. Can J Fish Aquat Sci 55:262-279

- Conan GY, Comeau M (1986) Functional maturity and terminal molt of male snow crab, Chionoecetes opilio. Can J Fish Aquat Sci 43:1710-1719

Conan GY, Comeau M, Gosset, C, Robichaud G, Garaïcoechea C (1994) The Bigouden Nephrops trawl, and the Devismes trawl, two otter trawls efficiency catching benthic stages of snow crab (Chionoecetes opilio), and American lobster (Homarus americanus). Can Tech Rep Fish Aquat Sci 1992

Dawe EG, Colbourne EB (2002) Distribution and demography of snow crab (Chionoecetes opilio) males on the Newfoundland and Labrador shelf. In: Paul AJ, Dawe EG, Elner R, Jamieson GS and others (eds) Crabs in cold water regions: biology, management, and economics. University of Alaska Sea Grant, AK-SG-02-01, Fairbanks, AK, p 577-594

Dawe EG, Taylor DM, Veitch PJ, Drew HJ, Beck PC, O'Keefe PG (1997) Status of Newfoundland and Labrador snow crab in 1996. DFO Can Sci Advis Sec Res Doc97/07, Ottawa

Dawe EG, Parsons DG, Colbourne EB (2008) Relationships of sea ice extent and bottom water temperature with abundance of snow crab (Chionoecetes opilio) on the Newfoundland-Labrador Shelf. ICES CM 2008:B02

> Dawe EG, Walsh SJ, Hynick EM (2010) Capture efficiency of a multispecies survey trawl for snow crab (Chionoecetes opilio) in the Newfoundland region. Fish Res 101: 70-79

Dawe E, Mullowney D, Stansbury D, Skanes K, and others (2011) An assessment of Newfoundland and Labrador snow crab (Chionoecetes opilio) in 2009. DFO Can Sci Advis Sec Res Doc 2011/073, Ottawa

Doubleday WG (1981) Manual on groundfish surveys in the northwest Atlantic. NAFO Sci Coun Studies 2:7-55

> Dutil JD, Dion C, Gamache L, Larocque R, Ouellet JF (2010) Ration and temperature effects on the condition of male adolescent molter and skip-molter snow crab. J Shellfish Res 29:1025-1033

Elner RW, Beninger PG (1992) The reproductive biology of snow crab, (Chionoecetes opilio): a synthesis of recent contributions. Am Zool 32:524-533

Elner RW, Beninger PG (1995) Multiple reproductive strategies in snow crab, Chionoecetes opilio: physiological pathways and behavioral plasticity. J Exp Mar Biol Ecol 193:93-112

Ennis GP, Hooper RG, Taylor DM (1990) Changes in the composition of snow crab (Chionoecetes opilio) participating in the annual breeding migration in Bonne Bay, Newfoundland. Can J Fish Aquat Sci 47:2242-2249

Ernst B, Armstrong DA, Burgos J, Orensanz JM (2012) Life history schedule and periodic recruitment of female snow crab (Chionoecetes opilio) in the eastern Bering Sea. Can J Fish Aquat Sci 69:532-550

Foyle TP, O'Dor RK, Elner RW (1989) Energetically defining the thermal limits of the snow crab. J Exp Biol 371-393

FRCC (Fisheries Resource Conservation Council) (2005) Strategic conservation framework for Atlantic snow crab. FRCC.05.R.1, Ottawa

Godbout G, Dutil JD, Hardy D, Munro J (2002) Growth and condition of post-moult male snow crab (Chionoecetes opilio) in the laboratory. Aquaculture 206:323-340

Hartnoll RG (1982) Growth. In: Abele LG (ed) The biology of crustacea, Vol. 2. Academic Press, New York, NY, p 11-96

Hartnoll RG, Bryant AD, Gould P (1993) Size distribution in spider crab populations: spatial and temporal variation. J Crustac Biol 13:647-655

Hébert M, Benhalima K, Miron G, Moryiasu M (2002) Moulting and growth of male snow crab Chionoecetes opilio (O. Fabricius, 1788) (Decapoda, Majidae), in the Southern Gulf of St. Lawrence. Crustaceana 75:671-702

Hébert $M$, Wade E, Biron $M$, DeGrâce $P$, Landry J-F, Moriyasu M (2011) The 2010 assessment of the snow crab (Chionoecetes opilio) stock in the southern Gulf of St. Lawrence (Areas 12, 19, 12 E and 12F). DFO Can Sci Advis Sec Res Doc 2011/082, Ottawa

Hines A (1989) Geographic variation in size at maturity in brachyuran crabs. Bull Mar Sci 45:356-368

Lovrich GA, Sainte-Marie B, Smith D (1995) Depth distribution and seasonal movements of Chionoecetes opilio (Brachura:Majidea) in Baie Sainte-Marguerite. Gulf of Saint Lawrence. Can J Zool 73:1712-1726

Marcello LA, Mueter FJ, Dawe EG, Moriyasu M (2012) Effects of temperature and gadid predation on snow crab recruitment: comparisons between the Bering Sea and Atlantic Canada. Mar Ecol Prog Ser 469:249-261

Maynard DR, Webber DM (1987) Monitoring the movements of snow crab (Chionoecetes opilio) with ultrasonic telemetry. Proc Oceans '87. The ocean-an international workplace 3:962-966

McCallum B, Walsh SJ (1996) Groundfish survey trawls used at the Northwest Atlantic Fisheries Centre, 1971present. NAFO Sci Coun Studies 29:93-103

Moriyasu M (2011) Review of the current status of the snow crab Chionoecetes opilio (O.Fabricius, 1788) fisheries and biological knowledge in eastern Canada. New frontiers in crustacean biology: Crustaceana Monographs 15: 95-107. Koninklijke Brill NV, Leiden

O'Halloran MJ, O'Dor RK (1988) Molt cycle of male snow crabs Chionoecetes opilio, from observations of external features, setal changes, and feeding behavior. J Crustac Biol 8:164-176

Orensanz JM, Ernst B, Armstrong DA (2007) Variation of female size and stage of maturity in snow crab (Chionecetes opilio) (Brachyura:Majidae) from the Eastern Bering Sea. J Crustac Biol 27:576-591

Paul A, Paul J (2001) Effects of temperature on length of intermolt periods in juvenile male Chionecetes bairdi. Alaska Fish Res Bull 8:132-134 
Sainte-Marie B, Gilbert D (1998) Possible effects of changes in CIL temperature and thickness on population dynamics of snow crab, Chionoecetes opilio, in the Gulf of St. Lawrence. DFO Can Sci Advis Sec Res Doc 98/38, Ottawa

Sainte-Marie B, Hazel F (1992) Moulting and mating of snow crabs, Chionoecetes opilio (O. Fabricius), in shallow waters of the northwestern Gulf of St. Lawrence. Can J Fish Aquat Sci 49:1282-1293

Sainte-Marie B, Raymond S, Brêthes J (1995) Growth and maturation of the benthic stages of male snow crab, Chionoecetes opilio (Brachyura: Majidae). Can J Fish Aquat Sci 52:903-924

Sainte-Marie B, Urbani N, Hazel F, Sévigny JM, Kuhnlein U (1999) Multiple choice criteria and the dynamics of assortative mating during the first breeding period of female snow crab Chionoecetes opilio (Brachyura, Majidae). Mar Ecol Prog Ser 181:141-153

Sainte-Marie B, Gosselin T, Sévigny JM, Urbani N (2008)

Submitted: November 2, 2011; Accepted: April 30, 2012
The snow crab mating system: opportunity for natural and unnatural selection in a changing environment. Bull Mar Sci 83:131-161

Taylor DM, Hooper RG, Ennis GP (1985) Biological aspects of the spring migration of snow crabs, Chionoecetes opilio, in Bonne Bay, Newfoundland (Canada). Fish Bull 83:707-711

Thompson RJ, Hawryluk M (1990) Physiological energetics of the snow crab, Chionecetes opilio. In: Proceedings of the International Symposium on King and Tanner crabs. Alaska Sea Grant College Program Report, AK-SG-9004, Fairbanks, AK, p 283-291

van der Meer J (2006) Metabolic theories in ecology. Trends Ecol Evol 21:136-140

Walsh SJ, McCallum BR (1996) Performance of the Campelen 1800 shrimp trawl during the 1995 Northwest Atlantic Fisheries Centre autumn groundfish survey. NAFO Sci Coun Studies 29:105-116

Proofs received from author(s): August 8, 2012 